\title{
A correlation study of the effectiveness of renal scintigraphy and sonography in the detection and evaluation of renal disorders
}

\author{
Maithaa H. Alsubhi \\ King Abdulaziz University \\ Atheer A. Alghanmi \\ King Abdulaziz University \\ Yara H. Alzabidi \\ King Abdulaziz University \\ Alhanouf K. Bafail \\ King Abdulaziz University \\ Saeed Muhammad Bafaraj ( $\nabla$ smbafaraj@kau.edu.sa ) \\ King Abdul Aziz University
}

Research article

Keywords: Renal disorders, Renal Scintigraphy, Sonography

Posted Date: August 4th, 2020

DOI: https://doi.org/10.21203/rs.3.rs-47493/v1

License: (c) (1) This work is licensed under a Creative Commons Attribution 4.0 International License. Read Full License 


\section{Abstract}

Background: This retrospective study was undertaken to assess correlation between renal scintigraphy employing technetium Tc-99m chelated with radiopharmaceutical drug Diethylenetriamine Penta Acetic Acid (DTPA) and renal ultrasonography morphological findings.

Methods: For this purpose, ninety six patients imaging data was statistically analyzed including 43 females and 53 males. All the patients were subjected to renal scintigraphy while 68 patients underwent renal ultrasonography. Renal U/S reported anatomical renal anomaly in $94.1 \%$ patients versus $85.4 \%$ detected by scintigraphy. There were 41 patients out of 68 diagnosed with hydronephrosis and 21 of them were suffering with mild hydronephrosis as suggested by U/S imaging.

Results: Renal scintigraphy of 41 hydronephrotic patients validated that 19 patients having nonobstructive bilateral pelvic dilation while remaining 22 with mild to severe obstruction. Ultrasonography diagnosed 4 patients with renal obstruction. Conversely, renal scintigraphy validated 2 of them with renal obstruction on the basis of renal function. In total, 19 out 96 patients were reported with renal obstruction through scintigraphy and validated obstruction in 1 of the 3 patients who were diagnosed with abnormal postvoid residual volume through $\mathrm{U} / \mathrm{S}$.

Conclusion: Renal scintigraphy is not significant in diagnosing kidney disease; rather this is a vibrant imaging tool providing supplementary data on the basis of renal function. Effectively targeted intervention regime can be achieved by correlating renal scintigraphy and renal ultrasonography results to minimize renal disease incidence.

\section{Background}

Renal disease poses global community health dilemma affecting more than 750 million people worldwide [1]. According to the Global Burden of Disease analysis reported in the year 2015, about 1.2 million individuals died from renal failure $[1,2]$. Each year, acute renal injury causes death of 1.7 million people. It has been estimated that 5-10 million people pass away each year from renal disease and reduced glomerular filtration rate contributes 18 million year of life loss and 19 million disability-adjusted life-years. Lack of public awareness campaigns and meager access to renal diagnostic services especially in underdeveloped countries perhaps undervalue the true threat posed by renal disease $[3,4,5]$. This whole scenario demands integrated intensive research to improve diagnosis of renal disease with minimal expenses in the field of renal diagnostics.

Evaluation of renal abnormalities through noninvasive procedures is top priority in clinical medicine for integrated management strategy to coupe abnormalities of kidney and its collecting system $[5,6]$. Ultrasound is a method of choice that has been used most frequently to diagnose urinary system malformations since last four decades and most of the renal abnormalities detected are anatomical in nature $[7,8]$. U/S is an application of Doppler Effect and does not involve administration of nephrotoxic contrast agents or radiation used to diagnose like polycystic kidney disease, pyelonephritis, crystal renal 
lesions, renal artery stenosis and hydronephrosis. On the other hand, $\mathrm{U} / \mathrm{S}$ is highly operator expertise oriented and results might be affected by extra-renal features such as arterial stiffness, atherosclerosis age, and BMI (Body Mass Index) $[8,9,10,11]$.

Renal scintigraphy is a robust non-invasive imaging tool to diagnose both functional and anatomical renal abnormalities such as urine leaks, urolithiasis, renal failure and tubular necrosis [12]. In this regard, several radiopharmaceutical drugs are accessible for scintigraphic evaluation including o-iodohippuric acid $(\mathrm{OIH})$ and mercapto-triacyl glycine (MAG3) to estimate tubular clearance and renal plasma flow, diethylene triamine penta-acetic acid (DTPA) as an indicator of glomerular filtration rate and dimercaptosuccinic acid to measure functional nephron mass. These radiopharmaceuticals are chelated with radio-active isotopes that emit gamma radiation when administered into the body and detected by gamma camera to generate 2D image. This technique is preferentially used to quantify relative function of each kidney $[13,14,15]$.

Although renal scintigraphy and ultrasound are correlated each time when imaging renal patients, but there has been no published literature on systematic investigation of correlation between these two methods for renal disease. Therefore, the present retrospective survey is intended to check renal anomalies spotted by ultrasonography when compared to scintigraphy in kidney disease. The major objective of this experiment is to find out the significance and effectiveness of renal scintigraphy and sonography to develop nuclear/ultrasound coupled clinical approach in diagnosing renal disease.

\section{Methods}

This retrospective survey was accepted by the Medical Ethical Review Committee of the King Abdulaziz University Hospital. It declared that current descriptive retrospective study jurisdiction does not fall under the Law on Medical Biosafety Research. Data records of 100 patients who underwent renal scintigraphy and renal ultrasonography at King Abdulaziz University Hospital from 2014 to 2019 were collected. Patients with age 18 years or more and suffering from any renal disease (excluding renal cancer) were included in the study.

Renal ultrasonography was performed by a radiologist using a transducer using a convex array transducer of 2.5-5 MHz. All the patients were requested to drink sufficient volume of fluid 1 hour prior to the renal sonography. Anterolateral kidneys scan was performed as patients exposed abdomen lying in supine position. For each kidney, transverse and anteroposterior dimensions were measured along with parenchymal thickness, presence of renal stones and dilation of renal pelvis were recorded. An anomaly pertaining to parenchymal echogenicity, hydronephrosis or anatomic renal malformations including a small-sized kidney, non-visualized kidney, double collecting system along with impaired corticomedullary distinction or enlarged urinary bladder was taken into account.

Patients were asked for intravenous fluid intake 30 to 60 minutes prior to injection and lie in supine position for renal scintigraphy. The patients were suggested to keep distance of 2 to 3 meter from other people for 24 hours after completion of the procedure. Radioisotope used for this study was Technetium 
Tc-99m chelated with radiopharmaceutical drug Diethylenetriamine Penta acetic Acid (DTPA). Patients were administered intravenously maximal dose of 5 milli Curie Tc-99m DTPA. A high-resolution gamma camera interfaced to a digital computer was used to capture radiations emitted by radioisotope and signals were converted into electronic form to generate 2D result. Dynamic images were obtained for 1 minute followed by injection of furosemide with subsequent dynamic images for 20 to 30 minutes. Timeactivity curves were generated on the basis of regions of interest related to the digital images of kidney. Renal malformations diagnosed through scintigraphy were explained in the form of delayed tracer handling, split renal function more than $10 \%$ between kidneys, renal scarring, functional size of kidneys, abnormal renogram, anatomic renal disorders including small kidney, non-visualized kidney, double collecting system and horseshoe kidneys.

The radiologist and nuclear physician were unaware of the outcomes of ultrasonography and scintigraphy respectively. The data were statistically analyzed using SPSS 21 software.

\section{Results}

According to the inclusion criteria, 96 patients were recruited who were suffering from different types of kidney disease. There were 53 males and 43 females.

The following section gives the demographic variable of the participants included in the research study $(\mathrm{N}=96)$, thus including the description of means, standard deviation and frequencies of their Age and Gender.

The mean age of the participants was 44.3 with SD 4.09. On the other hand, the mean of Gender of Participants is 1.6 with SD 0.13 . Whereas, mode is the most repeated value in the data, which is 49 in case of age and 2 in case of gender ( 2 for males and 1 for females) (Table 1 ).

Table 1: Mean and Standard Deviation of Demographic variables of participants $(\mathrm{N}=96)$.

\begin{tabular}{llll}
\hline Variable & $\mathrm{M}$ & $\mathrm{SD}$ & Mode \\
\hline Age & 44.3 & 4.09 & 49 \\
Gender & 1.6 & 0.13 & 2 \\
\hline
\end{tabular}

Note: $\mathrm{M}=$ Mean, $\mathrm{SD}=$ Standard Deviation, $\mathrm{M}=$ Mode

Table 2, described the correlation about Age and Gender of the patients with Genitourinary Disorder. The results exhibited that there is no significant difference in correlation between age and gender of the participants with Genitourinary System Disorder.

Table 2: Summary of Intercorrelations, for Age and Gender on Genitourinary System Disorder. (N=96) 


\begin{tabular}{llll}
\hline Factor & & 1 & 2 \\
\hline 1.1. & Age & 1 & - \\
& & & \\
1.2. & Gender & $-0.23(\mathrm{~ns})$ & 1 \\
\hline
\end{tabular}

Note: ${ }^{* * *} \mathrm{p}<.001, * * \mathrm{p}<.01, * \mathrm{p}<.05, \mathrm{p}>.05, \mathrm{~ns}=$ nonsignificant

Table 3, described the correlation among Age, Gender and Scintigraphy of the patients with Genitourinary System Disorder. The result of the analysis revealed that there was significant but negative relationship between age and scintigraphy of the patients.

Table 3: Summary of Intercorrelations, for Age, Gender and Scintigraphy on Genitourinary System Disorder

\begin{tabular}{llll}
\multicolumn{4}{c}{$(\mathrm{N}=96)}$. \\
Factor & 1 & 2 & 3 \\
\hline 1. Age & 1 & - & - \\
1. Gender & $-0.23(\mathrm{~ns})$ & 1 & - \\
2. Scintigraphy & $-0.03^{*}$ & $0.11(\mathrm{~ns})$ & 1 \\
\hline
\end{tabular}

Note: $* * * p<.001, * * \mathrm{p}<.01, * \mathrm{p}<.05, \mathrm{p}>.05, \mathrm{~ns}=$ nonsignificant

Table 4, described the correlation among Age, Gender and ultrasonography of the patients with Genitourinary System Disorder. The result revealed that there was significant but negative relationship between age and ultrasonography of the patients with genitourinary system disorder.

Table 4: Summary of Intercorrelations among Age, Gender and Ultrasonography on Patients with Genitourinary System Disorder $(\mathrm{N}=96)$.

\begin{tabular}{llll}
\hline Factor & 1 & 2 & 3 \\
\hline 1. Age & 1 & - & - \\
2. Gender & $-0.23(\mathrm{~ns})$ & 1 & - \\
3. Ultrasonography & $-0.00^{* * *}$ & $0.07(\mathrm{~ns})$ & 1 \\
\hline
\end{tabular}

Note: ${ }^{* * *} \mathrm{p}<.001,{ }^{* *} \mathrm{p}<.01,{ }^{*} \mathrm{p}<.05, \mathrm{p}>.05, \mathrm{~ns}=$ non significant 
All the patients underwent renal scintigraphy while ultrasonography was performed of 68 patients. The most prevalent clinical manifestation was hydronephrosis and renal obstruction. Through

ultrasonography, 41 patients were diagnosed with hydronephrosis out of 68. In case of renal scintigraphy, 19 patients were diagnosed with hydronephrosis out of 96 . On the other hand, post-void/pre-void residual volume was determined in 15 patients through ultrasonography. Renal US was found to be abnormal diagnosing different renal diseases in 64 patients with sensitivity of $94 \%$ while renal scintigraphy identified 82 patients with different renal diseases with an approximate sensitivity of $85 \%$. In renal ultrasonography, 4 patients were diagnosed with no renal disease out of 68 while in case of renal scintigraphy it was 14 out of 96 .

There were 4 patients reported with renal obstruction in ultrasonography out of 68 while renal scintigraphy diagnosed 2 of these 4 with renal obstruction on the basis of renal function.

Pre-void/post-void residual urine volume was determined in 15 patients through $\mathrm{U} / \mathrm{S}$ and 3 patients reflected abnormality in their post void residual urine volume which was more than $80 \mathrm{ml}$.

In total, 19 out of 96 renal disease patients were diagnosed with renal obstruction through renal scintigraphy.

\section{Discussion}

Renal disease is a universal threat distressing 750 million people globally and can cause complications like chronic kidney disease, hypertension, acute kidney injuries, proteinuria and kidney scarring $[1,16] \cdot$ The ultimate purpose of the cure is to prevent or decrease the complications of kidney disease. For normal adult, approximated blood flow is $500 \mathrm{~mL} / \mathrm{min}$ per kidney that is nearly $20 \%$ of cardiac output with blood volume of $50 \mathrm{ml} /$ kidney having $300-350 \mathrm{~mL} / \mathrm{min} / 100 \mathrm{~g}$ renal perfusion. In a healthy human, the Glomerular filtration rate (GFR) is $50-60 \mathrm{~mL} / \mathrm{min}$ per kidney and renal plasma flow (RPF) is $250-300$ $\mathrm{mL} / \mathrm{min}$ per kidney having filtration fraction (GFR/RPF) 0.2. Ageing results in decline of kidney function at an approximate rate of $1 \mathrm{~mL} / \mathrm{min}$ per year at age 40 years to ahead. Women experience quicker rate of decline when compared to men regarding this ageing parameter [17].

Accurate diagnosis of kidney disease proves bottleneck solely based on clinical and laboratory test. Many imaging techniques have been reported on the basis of their comparison and correlation studies to diagnose precisely renal malformations. For this purpose, ultrasonography is routinely practiced [18]. Voiding cystourethrography (VCUG) is recommended if ultrasonography diagnoses scarring, hydronephrosis or other findings suggestive of obstructive uropathy or vesicoureteral reflux [19]. Renal scintigraphy scan is a preferred diagnostic test to estimate GFR and blood flow in kidneys [20]. In most of the cases, renal US are effective to identify urinary tract abnormalities but not prioritized for renal parenchymal diagnosis [21].

Current study included 96 renal disease patients with 43 females and 53 females. All the patients underwent renal scintigraphy but 68 of them experienced U/S imaging procedure. The most commonly 
diagnosed manifestations were hydronephrosis and renal obstructions. Our results identified 41 patients out of 68 diagnosed with hydronephrosis through U/S imaging and 21 of them were suffering with mild hydronephrosis. Ultrasound is non-specific but sensitive and easy repeatability method to detect hydronephrosis due to the non-invasive nature. Such summarizing results show that there is possibility of differing levels of obstruction. The major diagnostic constraint of ultrasound is its failure to specify functional details. Ultrasound captures static images urinary systems that do not provide functional information $[22,23,24,25]$.

Relative kidney function can be quantified through radionuclide imaging and tubular agents are preferred to quantify relative kidney function and measure renal blood flow because of their efficient single transit excretion through renal arterial blood of kidney [26, 27]. Radiopharmaceutical Tc-99m-DTPA mixes in blood insignificantly binding with the plasma proteins and does not infiltrate red cells. Tc-99m-DTPA is small hydrophilic molecule which crosses capillary endothelium by employing passive diffusion mechanism ultimately distributing throughout the extracellular fluid volume. Renal scintigraphy GFR corresponds very well by 24-hour creatinine clearance because of extreme reproducibility throughTc $99 \mathrm{~m}$ DTPA renograms and Glomerular Filtration Rate measured concurrently by plasma disappearance [28]. While renal scintigraphy was performed of all those 41 hydronephrotic patients diagnosed through ultrasonography, 19 patients were diagnosed with non-obstructive bilateral pelvic dilation while remaining 22 with mild to severe obstruction. These results clearly classify hydronephrotic patients on functional basis providing precise information for effective management of renal disorders.

Renal scintigraphy results showed that hydronephrotic kidneys had almost regular or minor reduction in relative function. It is very essential to define the grade of hindrance. In this regard, ultrasound examination is not a preferred imaging technique to determine whether obstruction is responsible for hydronephrotic kidney or not [29]. In literature, several definitions have been reported of significant hydronephrosis and all such definition have common parameters including renal parenchyma, calices and pelvis. Consequently, renal ultrasonography, in conjunction with laboratory and clinical data, is more effective for the diagnosis of hydronephrosis. Moreover, we need renal scintigraphy for functional characterization of hydronephrosis to determine intervention guidelines [30, 31, 32].

There were 4 patients reported with renal obstruction in ultrasonography. When renal scintigraphy was performed, two patients were diagnosed with renal obstruction on the basis of renal function which clearly states that ultrasound is insensitive to discern between functional and anatomical impairment of renal disease [33]. In total, 19 out of 96 renal disease patients were diagnosed with renal obstruction which reinforces precise functional characterization analysis revealed by renal scintigraphy. Abnormal renal US observed in current study finding renal obstruction may be due to factors like interference by intestinal gas, ischemia, expertise of the radiologist and non-cooperation of the patients [34,35]. Moreover, one patient was reported non-obstructive renal disease in ultrasonography but was confirmed with renal obstruction in renal scintigraphy. Such false-negative results in ultrasonography may have happened due to obesity or partial venous obstruction [36]. The presence of more than one radiologist and lengthy duration of this study were not without consequence; nevertheless, these conditions well 
trigger real-life and non-experimental conditions. We suggest future prospective studies involving prolonged follow-up, age-specific results and comparative assessment of these two tests in order to deduce comprehensive findings and reduce limitations. Additionally, all-inclusive results will help identify the optimum imaging protocol for renal disease and will address whether non-concordance exists.

Substantial amount of postvoid residual volume can have many outcome symptoms like overflow incontinence, urinary frequency, recurrent urinary tract infections and nocturia. In some cases, measurement of postvoid residual volume is necessary to determine if there is any probability of renal disease. For this purpose, there is need for an accurate and rapid as well as non-invasive procedure as demanded by increasing scope of pharmacological treatment choices in urinary problems. Residual urine can be measured by catheterization of urethra but carries the risk of trauma and infection [37, 38, 39]. Ultrasonography has been a method of choice for evaluating the pre-void/post-void bladder volume since last three decades. Urinary bladder is hollow viscous, non-rigid and fenced by the pelvic arrangements that might restrict its growth potential in specified ways. It is supposed that an upsurge in size would cause a rise in at least one of the three directions [40]. Pre-void/post-void residual urine volume was determined in 15 patients of renal disease through ultrasonography and three patients reflected abnormality in their post void residual urine volume which was more than $80 \mathrm{ml}$. Renal scintigraphy results reported renal obstruction, bilaterally dilated non-obstructed pelvis and normal flow and function at both kidneys in all three patients respectively. One of the patients with normal flow and function at both kidneys but abnormal post void residual volume was diagnosed with enlarged prostate gland.

In the current study, $64 / 68$ patients were diagnosed with renal disease which is $94.1 \%$. As a result, the sensitivity of renal US in diagnosing renal disease was $94 \%$ while of renal scintigraphy was $85 \%$ because $82 / 96$ patients were diagnosed with renal disease. Therefore, it is recommended to use both of these imaging techniques to validate renal disease diagnosis from functional and anatomical perspective to augment the validation of result produced through either of the imaging techniques.

\section{Conclusion}

Renal scintigraphy is not remarkable to ultrasonography in diagnosing renal disorders; rather this is a vital imaging tool which is an objective method to highlight supplementary data on the kidney function. It distinguishes minute kidney pathology that might be not reported through kidney ultrasonography. Furthermore, although glomerular filtration rate falls in regular range, irregular kidney function of more sensitive method to detect imminent kidney dysfunction and demands steady follow up. The radiation dosage is quite low $(5 \mathrm{mCi})$ in contrast to other scintigraphy tests such as bone scintigraphy.

It is better if kidney disorder patients go through a standard scintigram after renal ultrasonography and serum creatinine. If scintigram is destructive for any kidney disease then no additional examination is essential. However, if scintigram is positive for a kidney disease, follow up examination will be mandatory in routine basis. A combination of functional and morphological imaging allows classification of patients into persons demanding aggressive intervention and persons falling into conservative management 
category. Early intervention can be made possible through precise diagnosis of renal disease by correlating renal scintigraphy and renal ultrasonography results.

\section{Declarations}

Ethics declarations and consent to participate: This study was approved by the Scientific Research Ethical Committee of King Abdulaziz University Hospital in a written form. The approval letter is attached for your reference.

Consent for publication: Not Applicable

Availability of data and materials: Please contact the corresponding author for information regarding additional data.

Competing interests: The authors declare no conflict of interest.

Funding: This research did not receive any specific grant from funding agencies in the public, commercial, or not-for-profit sectors.

\section{Authors Contributions:}

Writing and final editing: Saeed M. Bafaraj

Conceptualization: Maithaa H. Alsubhi

Formal Analysis: Atheer A. Alghanmi

Methodology and Investigation: Yara H. Alzabidi and Alhanouf K. Bafail

Acknowledgements: The authors are very thankful to supervisor Dr. Saeed Bafaraj for all his guidance, support, and cooperation to complete this research. Special thanks to Dr. Mohammad Wazzan for his support and assistance. Thanks to Mrs. Fatmah Bashraheel, and Miss leen Albalbeesi for their great and continuous support. Thanks to King Abdulaziz University Hospital and all personnel contributed.

\section{Author's Information:}

Maithaa H. Alsubhi ${ }^{1}$, Atheer A. Alghanmi ${ }^{1}$, Yara H. Alzabidi ${ }^{1}$, Alhanouf K. Bafail ${ }^{1}$, Saeed M. Bafaraj ${ }^{1 *}$

${ }^{1}$ Department of Diagnostic Radiology, Faculty of Applied Medical Sciences, King Abdulaziz University, Saudi Arabia

Email Addresses:

Maithaa H. Alsubhi: malsubhi0107@stu.kau.edu.sa 
Atheer A. Alghanmi: aalghanmi0086@stu.kau.edu.sa

Yara H. Alzabidi: yalzabidi@stu.kau.edu.sa

Alhanouf K. Bafail: abafil0001@stu.kau.edu.sa

Saeed M. Bafaraj: smbafaraj@kau.edu.sa

\section{References}

1. Ahmad K.A. Global, regional, and national disability-adjusted life-years (DALYs) for 315 diseases and injuries and healthy life expectancy (HALE), 1990-2015: a systematic analysis for the Global Burden of Disease Study 2015. Lancet 2016; 388:1603-58.

2. Wang H, Naghavi M, Allen C, Barber RM, Bhutta ZA, Carter A, et al. Global, regional, and national life expectancy, all-cause mortality, and cause-specific mortality for 249 causes of death, 1980-2015: a systematic analysis for the Global Burden of Disease Study 2015. Lancet 2016;388(10053):1459544.

3. Aigner F, De Zordo T, Pallwein-Prettner L, Junker D. Applications of technical fusion in uro-radiology. Rofo. 2015;187(5):331-7.

4. Arena S, Chimenz R, Centorrino A, Salamone I, Scuderi MG, Peri FM, et al. Conservative management in congenital severe bilateral hydronephrosis related to uretero-pelvic junction obstruction. J Biol Regul Homeost Agents. 2019;33:33-7.

5. Bazić-Đorović B, Radulović M, Šišić M, Jauković L, Dugonjić S, Pucar D, et al. Technetium-99mdimercaptosuccinic acid renal scintigraphy can guide clinical management in congenital hydronephrosis. Hell J Nucl Med. 2017;20:114-22.

6. Boddi M. Renal Ultrasound (and Doppler Sonography) in Hypertension: An Update. Adv Exp Med Biol. 2016;956:191-208.

7. Boubaker A, Prior JO, Meuwly JY, Bischof-Delaloye A. Radionuclide investigations of the urinary tract in the era of multimodality imaging. J Nucl Med. 2006;47:1819-36.

8. Ciofetta G, Gordon I, Piepsz A. Clinical applications of nuclear medicine. Arch Dis Child. 1988;63(3):321-8.

9. Crews D, Bello AK, Saadi G. Burden, Access, and Disparities in Kidney Disease. Kidney Int Rep. 2019;91(3):129-137.

10. Dhull RS, Joshi A, Saha A. Nuclear Imaging in Pediatric Kidney Diseases. Indian Pediatr. 2018;55(7):591-7.

11. Dowling KJ, Harmon EP, Ortenberg J, Polanco E, Evans BB. Ureteropelvic junction obstruction: the effect of pyeloplasty on renal function. J Urol. 1988;140(5):1227-30.

12. Durand E. Comparison of magnetic resonance imaging with radionuclide methods of evaluating the kidney. Semin Nucl Med. 2014;44(2):82-92. 
13. Grignon A, Filion R, Filiatrault D, Robitaille P, Homsy Y, Boutin H, et al. Urinary tract dilatation in utero: classification and clinical applications. Radiology 1986;160(3):645-7.

14. Hanssen O, Erpicum P, Lovinfosse P, Meunier P, Weekers L, Tshibanda L, et al. Non-invasive approaches in the diagnosis of acute rejection in kidney transplant recipients. Part I. In vivo imaging methods. Clin Kidney J. 2016;10:97-105.

15. Isiklar I, Aktas A, Akgun S, Karakayali H. From donor to recipient. Doppler US, power US and scintigraphy of kidney perfusion before and after transplantation. Acta Radiol. 2000;41(3):285-7.

16. Joshi R, John O, Jha V.The Potential Impact of Public Health Interventions in Preventing Kidney Disease. Semin Nephrol. 2017;37(3):234-44.

17. Kazlauskas V, Cekuolis A, Bilius V, Anglickis M, Verkauskas G. Diuretic Enhanced Ultrasonography in the Diagnosis of Pyeloureteral Obstruction. Medicina (Kaunas) 2019;55(10):e670.

18. Kjeldsen-Kragh J. Measurement of residual urine volume by means of ultrasonic scanning: a comparative study. Paraplegia 1988;26(3):192-9.

19. Kobayashi Y, Mishina H, Michihata N, Miyasaka M, Takayama Jl. Indication for voiding cystourethrography during first urinary tract infection. Pediatr Int. 2019;61:595-600.

20. Koratala A, Bhattacharya D, Kazory A. Point of care renal ultrasonography for the busy nephrologist: A pictorial review. World J Nephrol. 2019;8(3):44-58.

21. Krajewski W, Wojciechowska J, Dembowski J, Zdrojowy R, Szydelko T. Hydronephrosis in the course of ureteropelvic junction obstruction: An underestimated problem? Current opinions on the pathogenesis, diagnosis and treatment. Adv Clin Exp Med. 2017;26(5):857-64.

22. Kriegmair MC, Bergen T, Ritter M, Mandel P, Michel MS, et al. Digital Mapping of the Urinary Bladder: Potential for Standardized Cystoscopy Reports. Urology 2017;104:235-41.

23. Le Coz J, Orlandini S, Titomanlio L, Rinaldi VE. Point of care ultrasonography in the pediatric emergency department. Ital J Pediatr. 2018;44(1):87.

24. Li Y, You J. The research and application advances of medical imaging techniques in early renal function assessment of chronic kidney disease. Sheng Wu Yi Xue Gong Cheng Xue ZaZhi 2019;36:511-4.

25. Liyanage T, Ninomiya T, Jha V, Neal B, Patrice HM, Okpechi I, et al. Worldwide access to treatment for end-stage kidney disease: a systematic review. Lancet 2015;385(9981):1975-82.

26. Maibom SL, Holm ML, Rasmussen NK, Germer U, Joensen UN. Renal trauma: a 6-year retrospective review from a level 1 trauma center in Denmark. Scand J Urol. 2019;53(6):398-402.

27. Mehta RL, Cerdá J, Burdmann EA, Tonelli M, García-García G, Jha V, et al. International Society of Nephrology's Oby 25 initiative for acute kidney injury (zero preventable deaths by 2025): a human rights case for nephrology. Lancet 2015;385(9987):2616-43.

28. Murray CJ, Barber RM, Foreman KJ, AbbasogluOzgoren A, Abd-Allah F, Abera SF, et al. Global, regional, and national disability-adjusted life years (DALYs) for 306 diseases and injuries and healthy 
life expectancy (HALE) for 188 countries, 1990-2013: quantifying the epidemiological transition. Lancet 2015;386:2145-91.

29. Nitzsche EU, Zimmerhackl LB, Hawkins RA., Stover B, Frankenschmidt A, Sigmund G, et al. Correlation of ultrasound and renal scintigraphy in children with unilateral hydronephrosis in primary workup. Pediatr Nephrol. 1993;7(2):138-42.

30. Olson MC, Abel EJ, MankowskiGettle L. Contrast-Enhanced Ultrasound in Renal Imaging and Intervention. Curr Urol Rep. 2019;20(11):73.

31. Paltieli Y, Degani S, Aharoni A, Shapiro I, Reiter A, Scharf M, Weiss A. Ultrasound assessment of the bladder volume after anterior colporrhaphy. Gynecol Obstet Invest. 1989;28(4):209-11.

32. Pedersen JF, Bartrum RJ, Grytter C. Residual urine determination by ultrasonic scanning. Am J Roentgenol Radium Ther Nucl Med. 1975;125(2):474-8.

33. Peters AM, Perry L, Hooker CA, Howard B, Neilly MD, Seshadri N, et al. Extracellular fluid volume and glomerular filtration rate in 1878 healthy potential renal transplant donors: effects of age, gender, obesity and scaling. Nephrol Dial Transplant. 2012;27(4):1429-37.

34. Prigent A, Cosgriff P, Gates GF, Granerus G, Fine EJ, Itoh K, et al. Consensus report on quality control of quantitative measurements of renal function obtained from the renogram: International Consensus Committee from the Scientific Committee of Radionuclides in Nephrourology. Semin Nucl Med. 1999;29(2):146-59.

35. Rogasch JM, Bamm M, Bader M, Jaeschke E, Brenner W, van der Giet M, et al. Comparison of glomerular filtration rate (GFR) with Tc-99m-DTPA and tubular extraction rate (TER) with Tc-99mMAG3 in potential living kidney donors: Feasibility of a one-day protocol. Nuklearmedizin 2019;58(6):460-469.

36. Ruocco G, Palazzuoli A, Ter Maaten JM. The role of the kidney in acute and chronic heart failure. Heart Fail Rev. 2020;25(1):107-18.

37. Solomon DZ, Wasse A, Gorfu Y. Renal Arterial Doppler Resistive Index in Differentiating Obstructive and Non-Obstructive Hydronephrosis in Children at TikurAnbessaSpecialized Hospital, Ethiopia, October, 2018. Ethiop J Health Sci. 2019;29(5):591-596.

38. Stogianni A, Nikolopoulos P, Oikonomou I, Gatzola M, Balaris V, Farmakiotis D, et al.Childhood acute pyelonephritis: comparison of power Doppler sonography and Tc-DMSA scintigraphy. Pediatr Radiol. 2007;37(7):685-90.

39. Stroscio G, Impollonia D, Arrigo T, Sallemi A, Di Benedetto V, Scuderi MG, et al. Congenital renal anomalies imaging: a valuable tool for pediatricians. J Biol Regul Homeost Agents. 2019;33:7-11.

40. Yang JY, Sarwal RD, Fervenza FC, Sarwal MM, Lafayette RA. Noninvasive Urinary Monitoring of Progression in IgA Nephropathy. Int J Mol Sci. 2019;20(18):E4463. 